\title{
Cerebral amyloid angiopathy-related infarcts imitating high-grade differentiation of a benign meningioma
}

\author{
Piotr Talarczyk, ${ }^{1}$ Avinash Kumar Kanodia, ${ }^{1}$ James Ironside, ${ }^{2}$ David Mowle ${ }^{3}$
}

'Department of Radiology, Ninewells Hospital, Dundee, UK

${ }^{2}$ Department of Pathology, Western General Hospital, Edinburgh, UK

${ }^{3}$ Department of Neurosurgery, Ninewells Hospital, Dundee, UK

\section{Correspondence to} Dr Avinash Kumar Kanodia, avinash.kanodia@nhs.net

Accepted 5 September 2015

\section{DESCRIPTION}

Meningiomas are divided, by the WHO, into three groups: benign (grade I), atypical (grade II) and malignant (grade III). Although some overlapping features can occur, atypical meningiomas are more likely to exhibit heterogeneous density or intensity, heterogeneous contrast enhancement and relatively large perifocal oedema on CT scan and MRI. ${ }^{1}$ Meningiomas typically receive their blood supply from dural arteries, although larger meningiomas can also have a blood supply from leptomeningeal or parenchymal branches. Cerebral amyloid angiopathy (CAA) results from $\beta$-amyloid deposition in the walls of leptomeningeal and cortical arteries. ${ }^{2}$ It usually causes lobar intracerebral haemorrhage and often occurs in association with Alzheimer's disease.

Rarely, CAA has been documented to be associated with inflammatory changes, sometimes thought to be

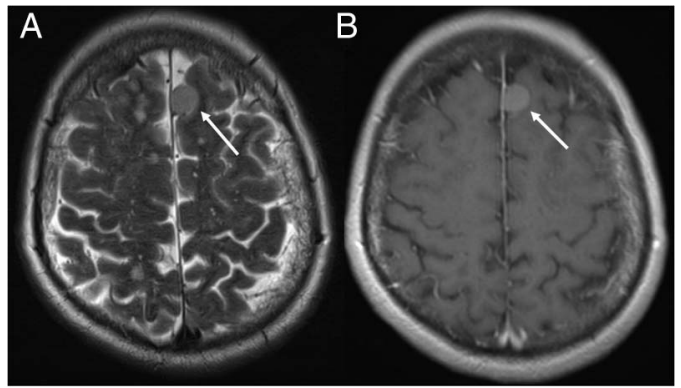

Figure 1 MRI in January 2011. T2 axial (A) and postcontrast T1 axial (B) images showing small left parafalcine meningioma (white arrow). co-existent primary central nervous system vasculitis or giant cell arteritis, although most literature has focused on probable inflammatory changes secondary to $\beta$-amyloid deposition, sometimes described as amyloid $\beta$-related angiitis. ${ }^{3-6}$ We could not find any specific association of CAA with Wegener's granulomatosis in the literature.

We present serial brain imaging findings describing the evolution of changes from a stable benign meningioma to a lesion imitating an atypical meningioma, which was surgically removed and subsequently shown to be affected by amyloid angiopathy.

A 59-year-old woman presented with a short history of right-sided tinnitus, hearing loss and sinusitis. Her other significant known condition was Wegener's granulomatosis involving the lungs, diagnosed in another institution. Brain MRI in January 2011 (figure 1) was negative for vestibular schwannoma, but demonstrated an incidental $14 \mathrm{~mm}$ parafalcine meningioma in the left frontal region on the background of small vessel cerebrovascular disease. MRI performed in March 2013 (figure 2), due to acute neurological symptoms, demonstrated extensive abnormalities in the right parieto-occipital lobe with further haemorrhage in the left frontal lobe; these were assumed to be due to the patient's known Wegener's granulomatosis, rather than from potential CAA. There was some increase in the size of the meningioma, which continued to show homogenous enhancement. A follow-up MRI in April 2014 (figure 3) showed further increase in size of the meningioma to $28 \mathrm{~mm}$, still with homogenous enhancement and without any significant surrounding brain changes.
To cite: Talarczyk $P$, Kanodia AK, Ironside J, et al. BMJ Case Rep Published online: [please include Day Month Year] doi:10.1136/bcr-2015211262

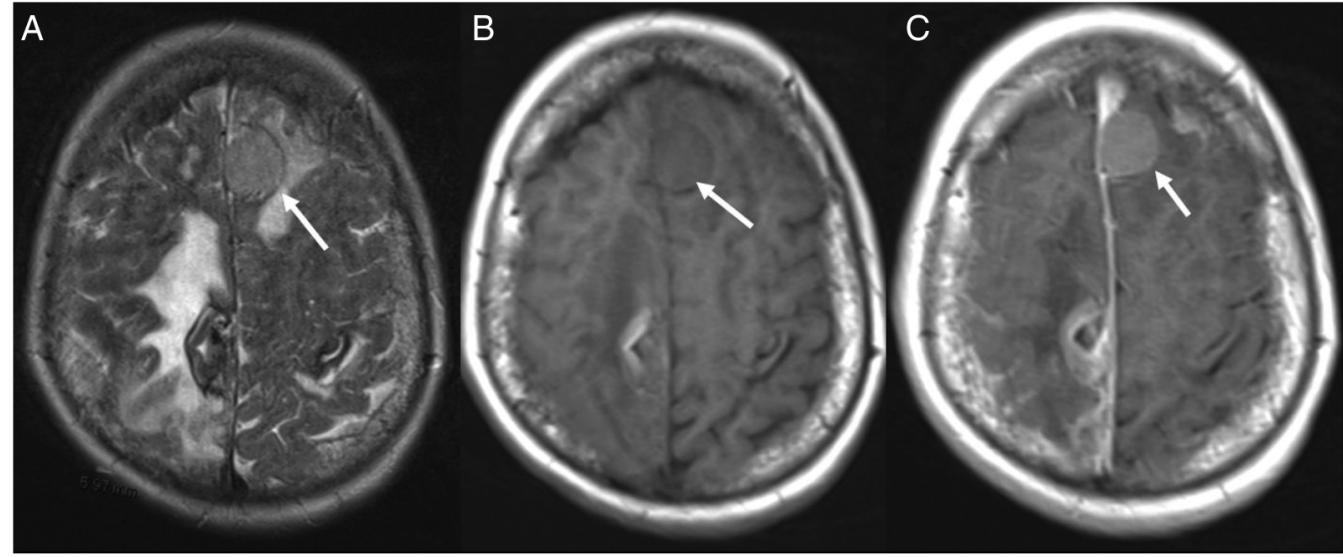

Figure 2 MRI in March 2013. T2 axial (A), precontrast and postcontrast T1 axial (B and C) images showing some increase in size of parafalcine meningioma (white arrow). Further brain changes with haemorrhages are also present. 


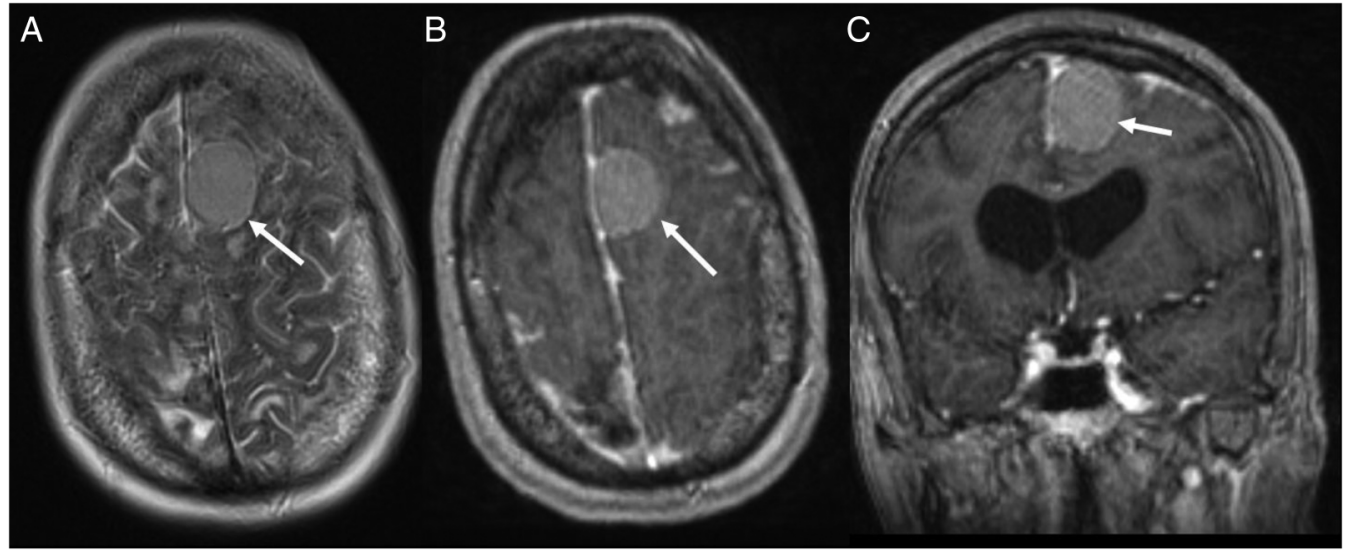

Figure 3 MRI in April 2014. T2 axial (A) and postcontrast T1 axial and coronal (B and C) images showing left parafalcine meningioma to have further slightly increased in size (white arrow).

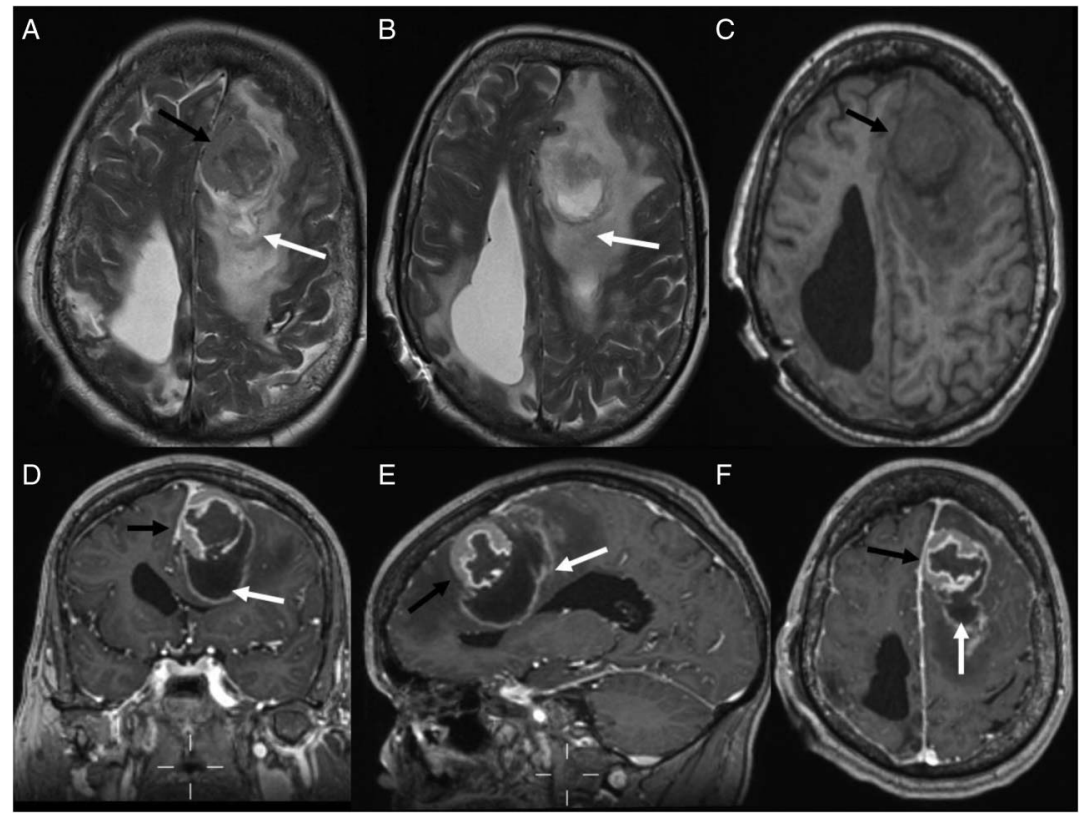

Figure 4 MRI in November 2014. T2 axial (A and B), precontrast T1 axial (C) and postcontrast coronal, sagittal and axial (D-F) images. Black arrows $(A, C-F)$ showing the heterogeneously enhancing meningioma with necrosis. White arrows $(A, B, D-F)$ showing underlying brain abnormalities with heterogeneity, necrosis and oedema.

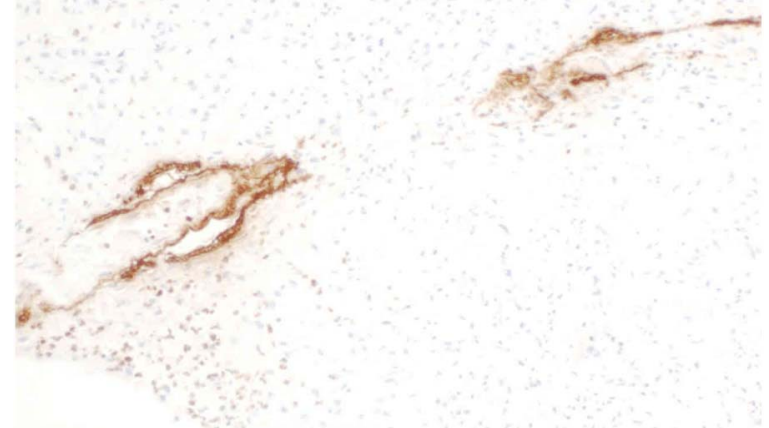

Figure 5 Immunohistochemistry for $\beta$-amyloid in the meningioma showing amyloid angiopathy in tumour vessel walls (brown), with splitting of the vessel wall and adjacent tumour infarction (lower left) $\times 100$.
In November 2014, the patient had further clinical deterioration with the new-onset right-sided neurological symptoms. MRI (figure 4) showed the meningioma as having a heterogeneous appearance, with necrosis and peripheral enhancement. The adjoining brain also appeared grossly heterogeneous and necrotic, with peripheral enhancement and significant mass effect. A neurosurgical review suspected the changes to be those of a high-grade tumour progression, and the meningioma was resected. Neuropathological examination found CAA involving vessels in the meninges, cortex and within the meningioma, resulting in infarcts in a WHO grade I meningioma and adjacent cortex without any invasion or other features of an atypical meningioma (figure 5). No evidence of vasculitis or Wegener's granulomatosis was found. A follow-up MRI in February 2015 (figure 6) demonstrated residual blood products with minimal postoperative enhancement and resolution of most of the surrounding changes.

The current case shows unusual appearances in a grade I meningioma resulting from leptomeningeal, cortical and 


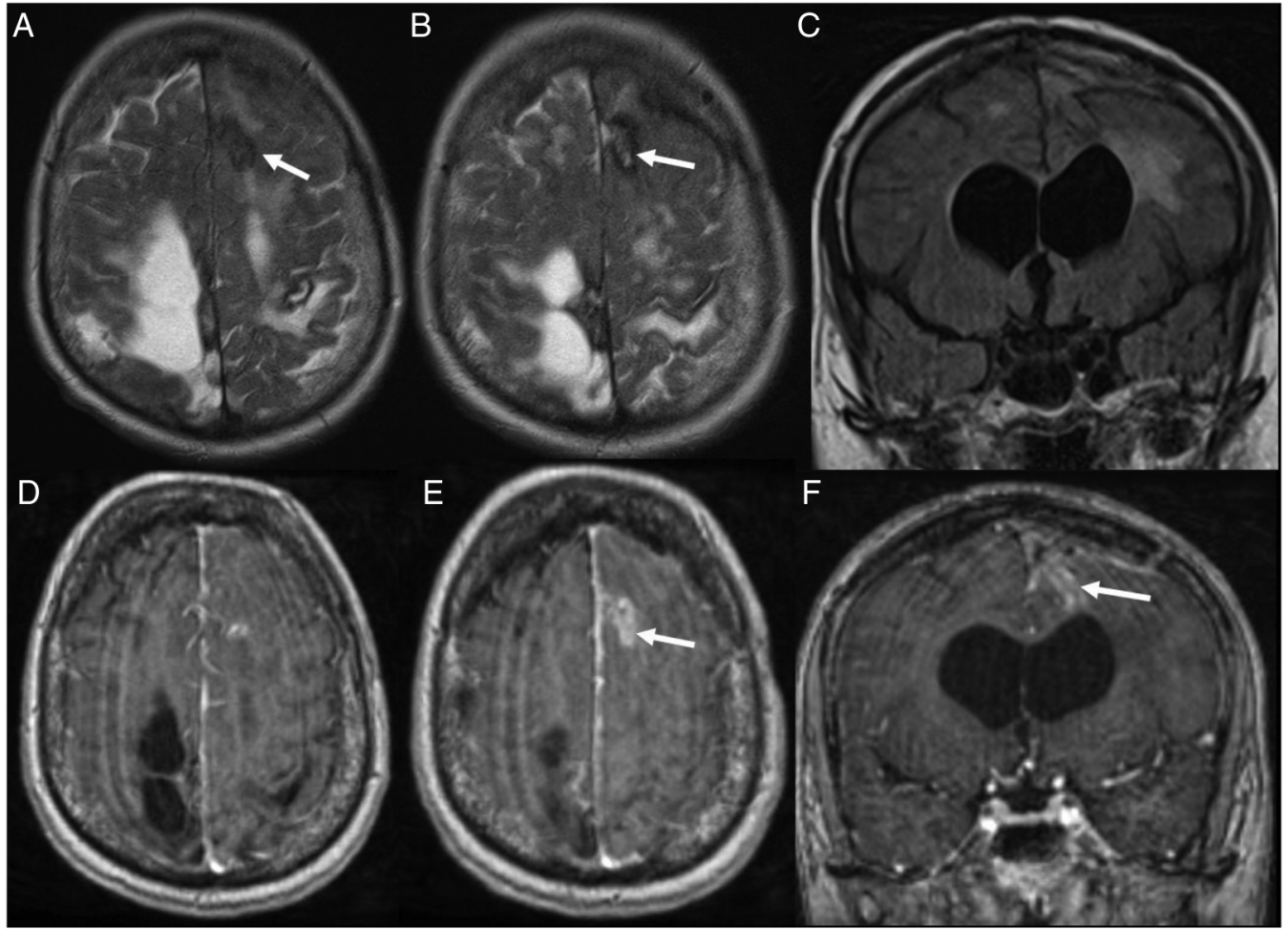

Figure $6 \mathrm{MRI}$ in February 2015 (postoperative). T2 axial (A and B), fluid-attenuated inversion recovery coronal (C), postcontrast T1 axial (D and E) and coronal (F) images showing residual changes with some haemosiderin deposition and minor residual enhancement (white arrow).

meningioma vessel involvement in amyloid angiopathy. These radiological appearances can easily be misinterpreted as an atypical meningioma. Involvement of blood vessels in a meningioma has not been previously described in CAA; it is otherwise a common condition in the elderly and should be kept in mind if other associated brain changes, such as lobar haemorrhages, are present in patients with a meningioma.

\section{Learning points}

- Infarcts in a WHO grade I meningioma can mimic high-grade differentiation, prompting neurosurgical concern.

- Cerebral amyloid angiopathy (CAA) can affect not only normal brain but also a pre-existing meningioma.

- Presence of brain changes consistent with CAA should prompt the suspicion of similar changes in a necrotic meningioma.
Competing interests None declared.

Patient consent Obtained.

Provenance and peer review Not commissioned; externally peer reviewed.

\section{REFERENCES}

1 Tomura N, Takahashi S, Sakuma I, et al. Neuroradiological findings of atypical meningiomas. CMIG Extra Cases 2004;28:33-9.

2 Pezzini A, Del Zotto E, Volonghi I, et al. Cerebral amyloid angiopathy: a common cause of cerebral hemorrhage. Curr Med Chem 2009;16:2498-513.

3 Morishige M, Abe T, Kamida T, et al. Cerebral vasculitis associated with amyloid angiopathy: case report. Neurol Med Chir (Tokyo) 2010;50:336-8.

4 Streichenberger N, Girard-Madoux P, Verejan I, et al. Giant cell angiitis of the central nervous system with amyloid angiopathy. A case report and review of the literature. Clin Exp Pathol 1999;47:311-17.

5 Sakaguchi H, Ueda A, Kosaka T, et al. Cerebral amyloid angiopathy-related inflammation presenting with steroid-responsive higher brain dysfunction: case report and review of the literature. J Neuroinflammation 2011:8:116.

6 Danve A, Grafe M, Deodhar A. Amyloid beta-related angiitis-a case report and comprehensive review of literature of 94 cases. Semin Arthritis Rheum 2014;44:86-92.

Copyright 2015 BMJ Publishing Group. All rights reserved. For permission to reuse any of this content visit

http://group.bmj.com/group/rights-licensing/permissions.

BMJ Case Report Fellows may re-use this article for personal use and teaching without any further permission.

Become a Fellow of BMJ Case Reports today and you can:

- Submit as many cases as you like

- Enjoy fast sympathetic peer review and rapid publication of accepted articles

- Access all the published articles

- Re-use any of the published material for personal use and teaching without further permission

For information on Institutional Fellowships contact consortiasales@bmjgroup.com

Visit casereports.bmj.com for more articles like this and to become a Fellow 